\title{
YIELD IMPROVEMENT FROM A SELECTION INDEX TECHNIQUE WITH COTTON
}

\author{
H. L. MANNING \\ Empire Cotton Growing Corporation, Uganda and the Institute of \\ Statistics, North Carolina State College, Raleigh
}

\section{INTRODUCTION}

Received 2.i.56

PLANT breeders can usually express their aims in simple terms of yield or quality, which affect the economic net worth of their crop. To attain these aims, however, requires measures of the traits involved and a system of weighting according to their phenotypic importance and their genetic variability and inter-relations. In the cotton breeding project here reported, quality was at a satisfactory level and improvement of yield was the main object. It was therefore easy to measure the important characters. There are three components of yield, namely, bolls per plant, seeds per boll and lint per seed. In breeding projects in which quality or disease resistance are of importance, objectivity, though difficult to achieve, should not be impossible.

Hazel and Lush (1942) have indicated that, when several traits affect the net worth of an organism, it is necessary to weight variations in those characteristics in the proper ratio if maximum progress from selection is to be obtained. A method for estimating optimum relative weights has been given by Fairfield Smith (1936), Hazel (r943) and Lerner et al. (1947) for various selection projects. More recently, Robinson et al. (I95 I) have given procedures for estimating genotypic and phenotypic covariances required for the construction of a selection index.

The primary purpose of this paper is to report on the results achieved by using a selection index technique with a continuously self-fertilised variety of cotton. The unexpected behaviour of an open-pollinated stock, maintained by a form of modal selection to furnish check yield standards, is also of some interest. Finally, there is some discussion relating to the persistence of genetic variability after seven generations of self-fertilisation.

\section{MATERIAL AND PROCEDURE}

The $\mathrm{BP}_{52}$ variety of cotton traces to a single plant selection from the Nyasaland Upland stock. It was maintained in open-pollinated bulks for ten years during which some selection was exercised for quality and yield. At the end of r 944 , about 800 plants were selected in a field, largely on the basis of sympodial habit and productivity, but also for leaf hairiness. Part of the seeds of each of the plants exhibiting the greatest leaf hairiness, was set aside in storage. Of the remainder, plants with seed cotton yield above the mean were bulked to form a new strain, then designated $\mathrm{BP}_{52} \mathrm{~B}$. An open-pollinated bulk of the descendants of this strain is now used as the check variety and has been designated $\mathrm{K} / 5 \mathrm{r}$. 
A mixture of $\mathrm{BP}_{52}$ material was made up from some of the stored selections, single plant produce from outlying stations in Uganda, some open-pollinated single plant selections made in commercial fields during the $1945-46$ season, and samples from the bulked seed of the commercial variety and $\mathrm{K} / 5 \mathrm{I}$. This material was planted in 1946 in an area of about $1 \frac{1}{2}$ acres, which would provide a population of about ten thousand plants. Four hundred and twenty plants were selected from this area, mainly on the basis of sympodial habit and of their apparent productivity. Reaping was confined to a single period when 35 to 50 per cent. of the plant produce was available. Twenty-three plants were outstanding for lint yield but with lint indices of not less than 3 centigrams of lint per seed. These gave 23 progenies which were grown in non-replicated rows in the following season. From these all subsequent progeny row material has descended. The remaining 397 plants were used to constitute a " modal " bulk check standard which will be described later.

The replicated progeny row system with cotton was first introduced by Hutchinson and Panse (1937) and has since been used extensively on stations of the Empire Cotton Growing Corporation. In this project, self-fertilised seed from each selected plant was divided into two parts. The first was grown in a replicated experiment, with a suitable number of replications, each plot containing ro or 12 plants at a spacing of 3 feet by 2 feet. Though from 3 to 5 seeds were sown in each hole, the plants were singled, after full emergence, some 15 to 20 days after planting. With 5 replications, progeny means would thus be based on from 50 to 60 plants. The remaining sister seed, of the original selected plant, was grown nearby in a single non-replicated row of from 30 to 60 plants all of which were self-fertilised. Progeny performance in the replicated trial provided the basis for selection. Representative plants were then picked in the non-replicated portions of the selected progenies, but it is not suggested that any significant advance was made by within progeny selection. In each of the past seven seasons from 30 to 81 progenies have been grown in either Randomised Complete Block or Lattice Square arrangements. The gain in efficiency from the latter has been so low that the simpler lay-out is now in general use.

The self-fertilised single plant selection (from the non-replicated row) of any one season becomes the parent of a progeny of from 70 to 120 plants. In turn the progeny of two or more Sib selections are said to belong to the same strain. Several strains are said to constitute a line when descended from a common great-grandparental plant. In this nomenclature, therefore, there may be lines, strains and progenies, originally from a single plant. Namulonge $\mathbf{B P}_{52}$ stocks are designated by the letter $\mathrm{C}$, followed by the year in which the particular material was grown as a progeny, and the serial number of the progeny in that year. Thus $\mathrm{C}_{50}$ (20) was the twentieth progeny of the 1950 series. For details see Fig. I.

Total lint yield was measured in the replicated trials (in contrast to the partial yield in modal bulks). This may require from 6 to ro reapings. A bolling index, though estimated separately for each plant, is given on a single plot basis, and is derived from counts of the mature bolls about the time of the first natural boll-split. A second trait, seeds per boll, is estimated from a 15 boll sample from each plot, obtained from the second and third reapings. A third trait, lint per seed (also known as lint index), is estimated from the entire produce, number of seeds being estimated from seed weight per seed in a roo seed sample.

Yield advance actually achieved, is tested in large scale trials with plot sizes of about $1 / 50$ acre. In one series of trials, bulked open-pollinated progenies are compared with a modal bulk check. The second series consists of thirteen $5 \times 5$ Latin squares at sites chosen to represent the soil types and climatic conditions experienced by the commercial crop. In consequence, strains are tested under a very much wider range of environmental conditions than the single experiment station where the programme was conducted. 


\section{CONSTRUCTION OF SELECTION INDEX \\ (i) Characters measured}

The objective of selection will always be to effect population changes in one or more traits which relate to the economic value of the organism. Whatever these traits may be some function of them will represent economic net worth, which may be symbolised as $W$. Since phenotype is conditioned by both genotype and environment, $\mathrm{W}$ may be represented as the sum

$$
\mathrm{W}=\mathrm{G}_{w}+\mathrm{E}_{w}
$$

where $\mathrm{G}_{w}$ is average genotypic net worth and $\mathrm{E}_{w}$ is a deviation from the average associated with the particular environment in which phenotype is observed. $\mathrm{G}_{w}$ is the quantity to be improved by selection. The most efficient basis for selection, i.e. the optimum selection index, would appear to be one having the largest possible correlation with $\mathrm{G}_{w^{*}}$. An obvious index would be $\mathrm{W}$ itself but intuition may often suggest that special attention be directed to characters having unique significance with respect to yield or quality. In fact any index of the form

$$
\mathrm{I}=b_{1} \mathrm{X}_{1}+b_{2} \mathrm{X}_{2}+\ldots b_{n} \mathrm{X}_{n}
$$

(where $\mathrm{X}_{1}, \mathrm{X}_{2}, \ldots \mathrm{X}_{n}$ represent objective measurements or numerical scores on any series of individual traits) may be considered. The magnitude of correlation $\rho \mathrm{IG}_{w}$, between an index and net worth provides a rational criterion for choice among indices; the index for which $\rho \mathrm{IG}_{w}$ is maximum being the superior one. Expressed differently, where net worth is affected by two or more individual traits, selection may be employed to alter the genotype in a variety of ways all of which may increase worth, but of these ways, which will differ because of relative emphasis placed on different traits, one will be the best because weighting is optimum.

Fairfield Smith (1936) and Hazel (1943) demonstrated that the optimum weights, $b_{1}, b_{2}, \ldots b_{n}$, to be given $n$ characters on which phenotypic data have been taken, are functions of (I) the genetic and phenotypic variances and covariances of the traits, and (2) the relative contributions of the traits to phenotypic net worth, all properly recognised. They showed that the optimum $b$ 's are obtained from the following set of equations solved simultaneously.

$$
\left.\begin{array}{l}
b_{1} t_{11}+b_{2} t_{12}+\ldots+b_{n} t_{1 n}=g_{1 w} \\
b_{2} t_{12}+b_{2} t_{22}+\ldots+b_{n} t_{2 n}=g_{2 w} \\
\cdot \\
\cdot \\
b_{n} t_{1 n}+b_{2} t_{2 n}+\ldots+b_{n} t_{n n}=g n_{w}
\end{array}\right\}
$$

where the $t$ 's are either phenotypic variances of progeny means for single traits $\left(t_{11}, t_{22} \ldots t_{n n}\right)$ or the corresponding phenotypic covariances for pairs of traits $\left(t_{12}, t_{13}, t_{23}\right.$, etc.) ; and $g_{1 w}, g_{2 w} \ldots g_{n w}$ are genetic 
covariances of $n$ single traits with net worth.* It should be emphasised that the parameters are defined with reference to the population of progenies in which selection is actually practised.

Procedures for estimation of the $t$ 's and $g$ 's and examples of selection indices have been given by Fairfield Smith (1936), Hazel (1943), Lerner et al. (1947) and Robinson et al. (1951). Details of the procedure followed in the work being reported will now be outlined. The traits used, bolls per plant, seeds per boll, lint per seed and total lint yield per plant, will hereafter be identified by subscripts I, 2,3 and $w$ respectively.

In view of the manner in which data on boll number and seeds per boll were obtained, a selection index might have used information on all four variables. However, anticipating that the major portion of the information about yield would be reflected in the remaining

TABLE I

Analysis of variance for bolls per plant $\mathrm{X}_{1}$ for the I954-55 season

\begin{tabular}{|c|c|c|c|}
\hline Variance source & d.f. & Mean square & $\begin{array}{l}\text { Expectation of } \\
\text { mean square }\end{array}$ \\
\hline $\begin{array}{l}\text { Replications } \\
\text { Lines } \\
\text { Strains } \\
\text { Progenies in strains } \\
\text { Plot error }\end{array}$ & $\begin{array}{r}3 \\
8 \\
4 \\
47 \\
177\end{array}$ & $\begin{array}{l}73 \cdot 60 \\
8 \cdot 5 \mathrm{I} \\
0 \cdot 31=M_{1} \\
2 \cdot 33=M_{2} \\
1 \cdot 86=M_{3}\end{array}$ & $\begin{array}{c}\cdots \\
\cdots \\
\sigma_{e}^{2}+r \sigma_{p}^{2}+r k_{o} \sigma_{s}^{2} \\
\sigma_{e}^{2}+r \sigma_{p}^{2} \\
\sigma_{s}^{2}\end{array}$ \\
\hline Total & 239 & $\ldots$ & $\ldots$ \\
\hline
\end{tabular}

Where $\sigma_{e}^{2}=$ plot error variance,

$\sigma_{p}^{2}=$ variance arising from genotypic differences among progenies of the same strain,

$\sigma_{s}{ }^{2}=$ variance arising from genotypic differences among strains of the same line,

$r=$ number of replications, and

$k_{0}=\frac{1}{n-1}\left[\Sigma k_{i}=\frac{\Sigma k_{i}{ }^{2}}{\Sigma k_{i}}\right] \quad$ where $k_{i}$ is the number of progenies in the $i$-th strain, (Snedecor, 1953).

three characters, only these were used in the index on which selection was actually based.

The variance for the bolls per plant data from the replicated progeny rows was analysed as shown in table $\mathrm{I}$ for the $1954-55$ season. Partition of degrees of freedom was as follows: The total for all progenies would be 59. Partition within these would be 8 d.f. for lines, 4 d.f. for strains and 47 d.f. between progenies in strains.

* Both Fairfield Smith and Hazel indicated that if net worth is a linear function of phenotype in individual traits, i.e. if

$$
\begin{aligned}
W & =a_{1} \mathrm{X}_{1}+a_{2} \mathrm{X}_{2}+\ldots a_{n} \mathrm{X}_{n} \text {, then } \\
g_{1 w 0} & =a_{1} g_{11}+a_{2} g_{12}+\ldots a_{n} g_{1 n} \\
g_{2 w} & =a_{2} g_{12}+a_{2} g_{22}+\ldots a_{n} g_{2 n}, \text { etc. }
\end{aligned}
$$

Here the $a$ 's are constants which represent the relative economic importance of the various individual traits. Note that what is here symbolised as $g_{1 w}, g_{2 w}$, etc. is symbolised by Fairfield Smith as $A_{1}, A_{2}$, etc. When $W$ is directly measurable in terms of a single trait, the most direct procedure for estimating the $b$ 's is through direct estimates of $g_{1 w}, g_{2 w}$ etc. used in the set of equations ( 1 ) given in the text. 
The estimates of phenotypic variances $\left(t_{11}, t_{22}\right.$ and $\left.t_{33}\right)$ substituted in equation ( $I$ ), were those for progenies within strains. They were computed directly from the "progenies in strains" mean square by division of the latter by the number of replications. Thus for the 1954-55 season

$$
t_{11}=2 \cdot 33 / 4=0.582
$$

The phenotypic covariances were obtained in a similar manner from analyses of covariance of the same form as the analysis of variance in table $\mathbf{~}$.

TABLE 2

Estimates of genotypic variances and covariances for 7 seasons

\begin{tabular}{|c|c|c|c|c|c|c|c|c|c|c|}
\hline Season & $\hat{g}_{11}$ & $\hat{g}_{22}$ & $\hat{g}_{33}$ & $\hat{g}_{w w}$ & $\hat{g}_{1 w}$ & $\hat{g}_{2 w}$ & $\hat{g}_{3 \omega}$ & $\hat{g}_{12}$ & $\hat{g}_{13}$ & $\hat{g}_{23}$ \\
\hline $\begin{array}{l}194^{8-49} \\
1949-50 \\
195^{0}-51 \\
195^{1-52} \\
195^{2}-53 \\
1953-54 \\
1954-55\end{array}$ & $\begin{array}{l}4 \cdot 619 \\
0 \\
0 \cdot 273 \\
3 \cdot 606 \\
0 \\
0 \cdot 218 \\
0 \cdot 118\end{array}$ & $\begin{array}{l}0.082 \\
0.436 \\
1.542 \\
0.452 \\
0.142 \\
0.536 \\
0.33^{8}\end{array}$ & $\begin{array}{l}0.0278 \\
0.0561 \\
0.055^{2} \\
0 \cdot 1054 \\
0.0250 \\
0.0119 \\
0.0139\end{array}$ & $\begin{array}{l}10.60_{4} \\
0.871 \\
0.613 \\
3.671 \\
0 \\
0.397 \\
0.505\end{array}$ & $\begin{array}{r}6.854 \\
-0.068 \\
0.272 \\
5.578 \\
-1.079 \\
0.257 \\
0.13^{8}\end{array}$ & $\begin{array}{r}0.3^{82} \\
0.040 \\
0.712 \\
-0.386 \\
-0.164 \\
0.225 \\
0.515\end{array}$ & $\begin{array}{r}0.310 \\
0.161 \\
0.025 \\
0.165 \\
-0.123 \\
-0.001 \\
-0.033\end{array}$ & $\begin{array}{r}-0.058 \\
-0.088 \\
0.659 \\
-0.362 \\
-0.192 \\
0.334 \\
0.149\end{array}$ & $\begin{array}{r}-0.074 \\
0.081 \\
-0.110 \\
-0.240 \\
-0.078 \\
-0.067 \\
-0.023\end{array}$ & $\begin{array}{l}-0.060 \\
-0.051 \\
-0.101 \\
-0.073 \\
-0.049 \\
-0.116 \\
-0.068\end{array}$ \\
\hline $\begin{array}{l}\text { Sums } \\
\text { Means }\end{array}$ & $\begin{array}{l}8 \cdot 834 \\
I \cdot 262\end{array}$ & $\begin{array}{l}3.53^{8} \\
0.504\end{array}$ & $\begin{array}{l}0 \cdot 2953 \\
0 \cdot 0422\end{array}$ & $\begin{array}{r}I 6 \cdot 66 \mathrm{I} \\
2 \cdot 38 \mathrm{o}\end{array}$ & $\begin{array}{l}9 \cdot 95^{2} \\
1 \cdot 422\end{array}$ & $\begin{array}{l}I \cdot 324 \\
0 \cdot 189\end{array}$ & $\begin{array}{l}0.504 \\
0 \cdot 072\end{array}$ & $\begin{array}{l}0.442 \\
0.063\end{array}$ & $\begin{array}{l}-0.511 \\
-0.073\end{array}$ & $\begin{array}{l}-0.518 \\
-0.074\end{array}$ \\
\hline
\end{tabular}

TABLE 3

Estimates of phenotypic variances and covariances for 7 seasons

\begin{tabular}{|c|c|c|c|c|c|c|c|c|c|c|}
\hline Season & $t_{11}$ & $t_{22}$ & $t_{33}$ & $t_{1000}$ & $t_{1 w}$ & $t_{2 w}$ & $t_{3 w}$ & $t_{12}$ & $t_{13}$ & $t_{23}$ \\
\hline $\begin{array}{l}194^{8-49} \\
1949^{-50} \\
195^{0-5} 1 \\
195^{1-52} \\
195^{2-53} \\
1953-54 \\
1954-55\end{array}$ & $\begin{array}{l}7 \cdot 29^{*} \\
4 \cdot 590 \\
1 \cdot 028 \\
6 \cdot 717^{*} \\
0 \cdot 785 \\
1 \cdot 801 \\
0 \cdot 582\end{array}$ & $\begin{array}{l}0 \cdot 927 \\
1 \cdot 259 \\
2 \cdot 157 * \\
1 \cdot 253 \dagger \\
0 \cdot 689 \\
0 \cdot 903^{*} \\
1 \cdot 315\end{array}$ & $\begin{array}{l}0.0480^{*} \\
0.0753^{*} \\
0.0659^{*} \\
0.1228^{*} \\
0.0374^{*} \\
0.0322 \dagger \\
0.0404 \dagger\end{array}$ & $\begin{array}{c}14 \cdot 618 * \\
4 \cdot 597 \\
2 \cdot 77^{2} \\
7 \cdot 591^{*} \\
1 \cdot 963 \\
2 \cdot 4^{89} \\
1 \cdot 535 \dagger\end{array}$ & $\begin{array}{l}9 \cdot 848 \\
2 \cdot 642 \\
1 \cdot 098 \\
5 \cdot 470 \\
0 \cdot 071 \\
1 \cdot 691 \\
0 \cdot 650\end{array}$ & $\begin{array}{l}0.046 \\
0.075 \\
0.915 \\
0.102 \\
0 \cdot 077 \\
0.274 \\
0.555\end{array}$ & $\begin{array}{r}0.316 \\
0.244 \\
0.077 \\
0.261 \\
-0.097 \\
0.043 \\
-0.009\end{array}$ & $\begin{array}{r}-0.121 \\
0.124 \\
0.566 \\
-0.183 \\
-0.050 \\
-0.176 \\
0.004\end{array}$ & $\begin{array}{r}0.090 \\
-0.020 \\
-0.083 \\
-0.183 \\
-0.078 \\
-0.070 \\
-0.015\end{array}$ & $\begin{array}{l}-0.087 \\
-0.077 \\
-0.120 \\
-0.082 \\
-0.054 \\
-0.007 \\
-0.077\end{array}$ \\
\hline $\begin{array}{l}\text { Sums } \\
\text { Means }\end{array}$ & $\begin{array}{r}22 \cdot 801 \\
3 \cdot 257\end{array}$ & $\begin{array}{l}8 \cdot 503 \\
1 \cdot 215\end{array}$ & $\begin{array}{l}0.4220 \\
0.0602\end{array}$ & $\begin{array}{r}35 \cdot 565 \\
5 \cdot 081\end{array}$ & $\begin{array}{r}21 \cdot 470 \\
3 \cdot 067\end{array}$ & $\begin{array}{l}2 \cdot 044 \\
0 \cdot 292\end{array}$ & $\begin{array}{l}0.925 \\
0.13^{2}\end{array}$ & $\begin{array}{l}0.164 \\
0.023\end{array}$ & $\begin{array}{l}-0.359 \\
-0.051\end{array}$ & $\begin{array}{l}-0.504 \\
-0.072\end{array}$ \\
\hline
\end{tabular}

$$
\text { Progenies in strains } p=0.01^{*} ; p=0.05 \dagger
$$

$\sigma_{p}^{2}$ was estimated by equating the "progenies in strains" and "plot error" mean squares to their expectations, with the result that $\left(\mathbf{M}_{2}-\mathbf{M}_{3}\right) / r$ provides estimates of the desired parameters. Thus again for the 1954-55 season, the estimate of

$$
\sigma_{p}{ }^{2}=(2 \cdot 33-1 \cdot 86) / 4=0 \cdot 118 .
$$

Corresponding estimates of covariances, due to genotypic differences among progenies of the same strain, were obtained in a similar manner from analyses of covariance. Estimates of $\sigma_{p}{ }^{2}$ for the three 
traits and worth itself and the corresponding covariances are listed in table 2 for all seasons. These are designated $\hat{g}_{11}, \hat{g}_{22}$, etc. for variances and $\hat{g}_{12}, \hat{g}_{13}, \hat{g}_{1 w}$ for covariances in as much as they were estimates employed in computation of the selection indices.

Table 3 represents estimates of phenotypic variances and covariances.

\section{(ii) Computation of the $b$ coefficients}

Substituting the estimates of $\hat{g}_{1 w}, \hat{g}_{2 w}$ and $\hat{g}_{3 w}$, and the $t$ 's from tables 2 and 3 , in the simultaneous equations for estimating the $b$ coefficients we have for the 1954-55 season,

$$
\begin{array}{rr}
0.0582 b_{1}+0.004 b_{2}-0.015 b_{3}= & 0.138 \\
0.004 b_{1}+1.315 b_{2}-0.077 b_{3}= & 0.515 \\
-0.015 b_{1}-0.077 b_{2}+0.040 b_{3}= & -0.033
\end{array}
$$

The solution of these simultaneous equations was obtained by the

\begin{tabular}{|c|c|c|c|c|c|c|}
\hline \multirow{2}{*}{ Season } & \multirow{2}{*}{ Series } & \multicolumn{2}{|c|}{ Progenies } & \multicolumn{3}{|c|}{ Coefficients } \\
\hline & & Grown & Selected & $b_{1}$ & $b_{2}$ & $b_{3}$ \\
\hline $\begin{array}{l}1948-49 \\
1949-50 \\
1950-51 \\
195-52 \\
1952-53 \\
1935-54 \\
1954-55\end{array}$ & $\begin{array}{l}\mathrm{C}(48) \\
\mathrm{C}(49) \\
\mathrm{C}(50) \\
\left.\mathrm{C}_{51}\right) \\
\mathrm{C}(52) \\
\mathrm{C}(53) \\
\mathrm{C}(54)\end{array}$ & $\begin{array}{l}38 \\
44 \\
30 \\
44 \\
43 \\
65 \\
58\end{array}$ & $\begin{array}{r}12 \\
6 \\
6 \\
10 \\
8 \\
9 \\
9 \\
14\end{array}$ & $\begin{array}{r}0 \cdot 872 \\
-0 \cdot 009 \\
0 \cdot 170 \\
0 \cdot 599 \\
-2 \cdot 475 \\
0 \cdot 178 \\
0 \cdot 236\end{array}$ & $\begin{array}{r}\mathrm{r} \cdot 179 \\
0.145 \\
0 \cdot 305 \\
-0.057 \\
-0.057 \\
-1 \cdot 222 \\
0.290 \\
0 \cdot 392\end{array}$ & $\begin{array}{r}6.958 \\
0.232 \\
1.254 \\
2.481 \\
-10.253 \\
0.444 \\
0.015\end{array}$ \\
\hline
\end{tabular}

TABLE 4

b coefficients actually used for selection

method outlined by Goulden (1939), known as the abbreviated Doolittle method. The coefficients were

$$
b_{1}=0.236 \quad b_{2}=0.392 \quad b_{3}=0.015
$$

which indicates that the selection index should be

$$
\mathrm{I}=0.236 \mathrm{X}_{1}+0.392 \mathrm{X}_{2}+0.015 \mathrm{X}_{3} \text { where } \mathrm{X}_{1}, \mathrm{X}_{2} \text { and } \mathrm{X}_{3}
$$

are separate values for each trait for each progeny and are means of the number of replications employed. Values for the $b$ coefficients for 7 seasons are summarised in table 4 .

\section{RESULTS}

\section{(i) Basis of expectation}

The expected mean genetic superiority of progenies, selected on the basis of an index in which traits are given optimum weights, is

$$
k \sqrt{b_{1} g_{1 w}+b_{2} g_{2 w}+b_{3} g_{3 w}} \ldots
$$

where $k=\left(\overline{\mathbf{I}}_{S}-\overline{\mathbf{I}}\right) / \sigma_{\mathrm{I}}, \mathbf{I}$ is the mean of the selection index of all 
progenies, $I_{S}$ is the corresponding mean for selected progenies, and $\sigma_{1}$ is the standard deviation of individual values of I. Thus $k$ is the selection differential expressed in terms of standard deviation units.*

Exactly optimum weights would be possible only if true values of the $g$ 's and $t$ 's were known. Since estimates must be employed weights computed are unlikely ever to be optimum though they may be satisfactory approximations. In this case, the expected genetic superiority of selections can be shown to be

$$
\frac{k}{\sigma_{1}}\left(b_{1} g_{1 w}+b_{2} g_{2 w}+b_{3} g_{3 w}\right) \ldots \text {. . . . }
$$

As was indicated in the previous section, the computation of the $b$ coefficients in this breeding programme was based on estimates of variances and covariances among progenies within strains. On the other hand selection was actually practised among all progenies without reference to strain. Thus the effective population in which selection occurred was one comprised of progenies belonging to different strains. The effective parameters were those descriptive of the variation of

TABLE 5

Analysis of covariance in bolls per plant $\left(X_{1}\right)$ and yield $\left(X_{w}\right)$ for $1954-55$

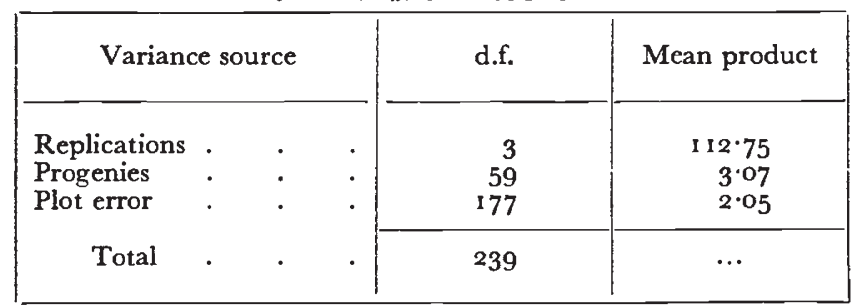

progenies among, as well as within strains. Consequently, substitution of estimates of $\hat{g}_{1 w}^{\prime}, \hat{g}^{\prime}{ }_{2 w}$ and $\hat{g}_{3 w}^{\prime}$ based on the total variation (including that among lines and strains) in equation $(2 b)$ provides the proper basis for predicting the effect of the selection practised in this programme. The estimates were obtained from analyses of covariance of the form exemplified in table 5 in terms of the data for bolls per plant and yield, from the r $954-55$ season. Here the line and strain contributions have not been separated from the total for progenies. The genetic covariance, $\hat{g}^{\prime}{ }_{1}$, was estimated as the difference between the mean products for progenies and plot error divided by the number of replications. Thus

$$
\begin{aligned}
\hat{g}_{1 w}^{\prime} & =(3.07-2.05) / 4=0.254 . \quad \text { Similarly } \\
\hat{g}_{2 w} & =0.350 \text { and } \hat{g}_{3 w}=0.030 .
\end{aligned}
$$

* In the case of selection already practised, $k$ can be computed from the data. However, when future selection is being considered, this cannot be done and a probable value is required. The procedure used was to assume normal distribution of the progeny selection index values. With such assumption the expectation of $k$ is given by $z / q$. Here $q$ is the fraction selected, and $z$ is the height of the ordinate which divides the area of the normal curve into portions $q$ and $1-q$. The required ordinate for a given $q$ can be found from tables of area and ordinates of the normal curve of error such as tables $I$ and II given by Fisher and Yates (1948). 
The predicted annual yield increments are given in table 6, together with other data relevant to its estimation.

While the estimates of genetic advance resulting from selection in a single year do not appear impressive, the cumulative estimate shown in the final column is of appreciable magnitude. The results obtained in the progeny bulks and district variety trials provide realistic checks of the actual improvement effected.

\section{(ii) The behaviour of the modal bulk}

It was thought that bulking of material, "modal " for several traits, would provide a relatively stable check variety which was considered to be essential as a basis for measured advance from selection. The method employed was as follows : after withdrawal

TABLE 6

Expected genetic superiority by seasons. With $\mathrm{b}$ coefficients used and genetic covariances for all progenies

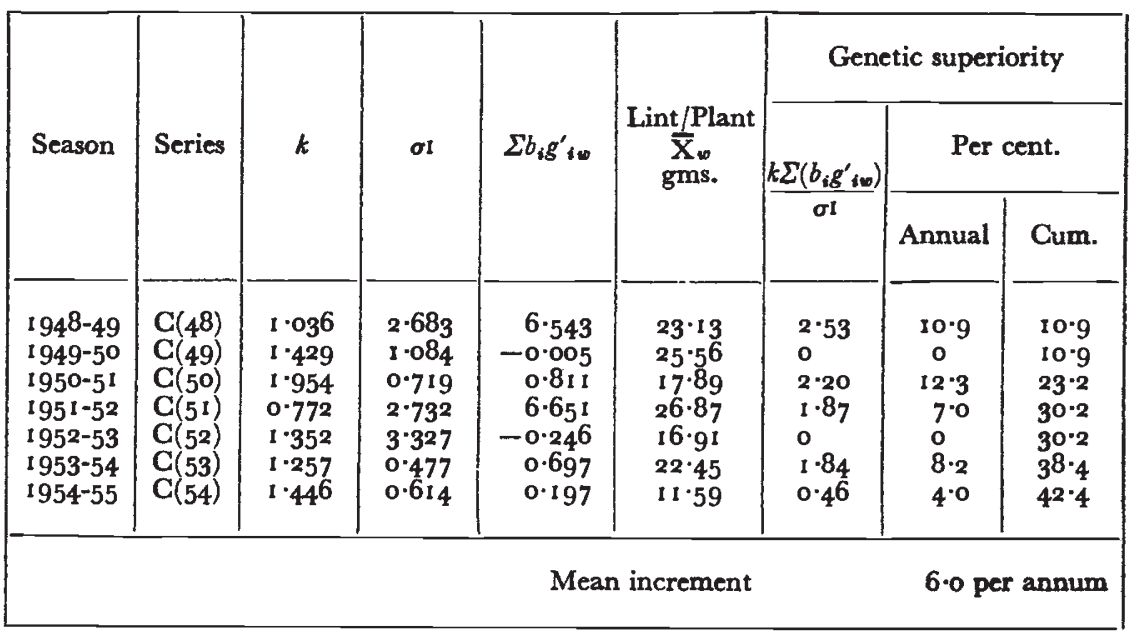

of the 23 plants for the $1947-4^{8}$ progeny rows, the mean and standard deviation of the remaining 397 plants were calculated for the trait lint per seed. All plants deviating from the mean by more than one standard deviation were then eliminated. The mean and standard deviation, for the trait lint length, were then calculated on the plants which remained. Again those deviating by more than one standard deviation were eliminated. There remained 2 II plants from which all seed was bulked and this was grown during the 1948-49 season as the first modal bulk ( $I-M B)$. Samples of this seed and that from discarded plants were mixed, approximately in the proportion of selected to unselected plants, to provide material which may be designated zero modal bulk (o-MB). This was placed in storage.

Seed for the next modal bulk (2-MB) - and all later modal bulkswas obtained in a slightly different manner. About 500 plants (later 
reduced to 300) were selected by field workers. Lint per plant and lint per seed were again recorded for each plant. Plants deviating from the mean by more than one standard deviation were eliminated. Seed weight per seed was then determined on the plants which remained and, after a similar elimination, lint length was estimated on those which remained. This process, always in the same sequence, has been repeated in successive seasons and, contrary to expectation, the mean lint per plant of those which remained after the third process of elimination has, for each season, been higher than the mean of all plants chosen in the field.

The zero modal bulk seed collected in 1947 and placed in storage was grown in the 1953-54 season. The plants were self-fertilised and seed produced was bulked. This fresh seed and a sample of $7-\mathrm{MB}$ were included as extra entries in the replicated progeny row trial of the $1954-55$ season. Mean lint yields in grams of lint per plant from

TABLE 7

Comparative yields of selected progenies in bulks trials

\begin{tabular}{|c|c|c|c|c|c|c|}
\hline \multirow{2}{*}{ Season } & \multirow{2}{*}{ Series } & \multicolumn{2}{|c|}{ Number of replications } & \multicolumn{2}{|c|}{ Mean lint yield per acre } & \multirow{2}{*}{$\begin{array}{l}\text { Increment } \\
\text { per cent. }\end{array}$} \\
\hline & & Locations & $\begin{array}{c}\text { Per } \\
\text { location }\end{array}$ & Standard & $\begin{array}{c}\text { Selected } \\
\text { progenies * }\end{array}$ & \\
\hline $\begin{array}{l}1949-50 \\
1950-51 \\
1951-5^{2} \\
195^{2}-53 \\
1953-54 \\
1954-55\end{array}$ & $\begin{array}{l}\mathrm{C}\left(4^{8}\right) \\
\mathrm{C}(49) \\
\mathrm{C}\left(5^{0}\right) \\
\mathrm{C}\left(5^{1}\right) \\
\mathrm{C}\left(5^{2}\right) \\
\mathrm{C}\left(5^{2}\right)\end{array}$ & $\begin{array}{r}1 \\
1 \\
6 \\
4 \\
6 \\
10\end{array}$ & $\begin{array}{l}6 \\
5 \\
3 \\
3 \\
3 \\
3\end{array}$ & $\begin{array}{l}289(1-M B) \\
233(2-M B) \\
370(3-M B) \\
267(4-M B) \\
244(5-M B) \\
127(6-M B)\end{array}$ & $\begin{array}{l}313 \\
245 \\
411 \\
274 \\
267 \\
155\end{array}$ & $\begin{array}{r}8 \cdot 3 \\
5 \cdot 2 \\
11 \cdot 1 \\
2 \cdot 6 \\
9 \cdot 4 \\
22 \cdot 0\end{array}$ \\
\hline
\end{tabular}

* All progenies selected during preceding season.

four replications were $9 \cdot 20$ for o-MB and $12 \cdot 0$ for $7-\mathrm{MB}$, an advantage of $30 \cdot 2$ per cent. for the latter, or an average of 4.3 per cent. per year.

In $1949-50$, both $\mathrm{K} / 5^{\mathrm{I}}$ and $\mathrm{I}-\mathrm{MB}$ were included in district variety trials at $\mathrm{I} 3$ centres, and in the $1953-54$ season, $\mathrm{K} / 5^{\mathrm{I}}$ and 5 -MB were entries in progeny bulks trials at six locations. Mean lint yields (in lb. per acre) were as follows :-

$\begin{array}{rccc}\text { Year } & \mathrm{K} / 5 \mathrm{I} & \mathrm{I}-\mathrm{MB} & 5 \text {-MB } \\ \mathrm{I} 949-50 & 294 & 289 & \ldots \\ \mathrm{I} 953-54 & 335 & \ldots & 368\end{array}$

Accepting $\mathrm{K} / 5 \mathrm{I}$ as a standard of comparison, an increase of Io per cent. over four generations of the modal bulk is indicated. This amounts to 2.5 per cent. per year as compared to the 4.3 per cent. estimate derived from comparison of o-MB and $7-\mathrm{MB}$. These results suggest an effective mechanism of positive selection for yield in the modal bulk population. 
(iii) Yield advance of the progeny row material

Progeny bulks trials were conducted in six seasons beginning with 1949-50. Numbers of locations in which trials were grown, of replications at each location and mean yields over all locations, are presented in table 7 .

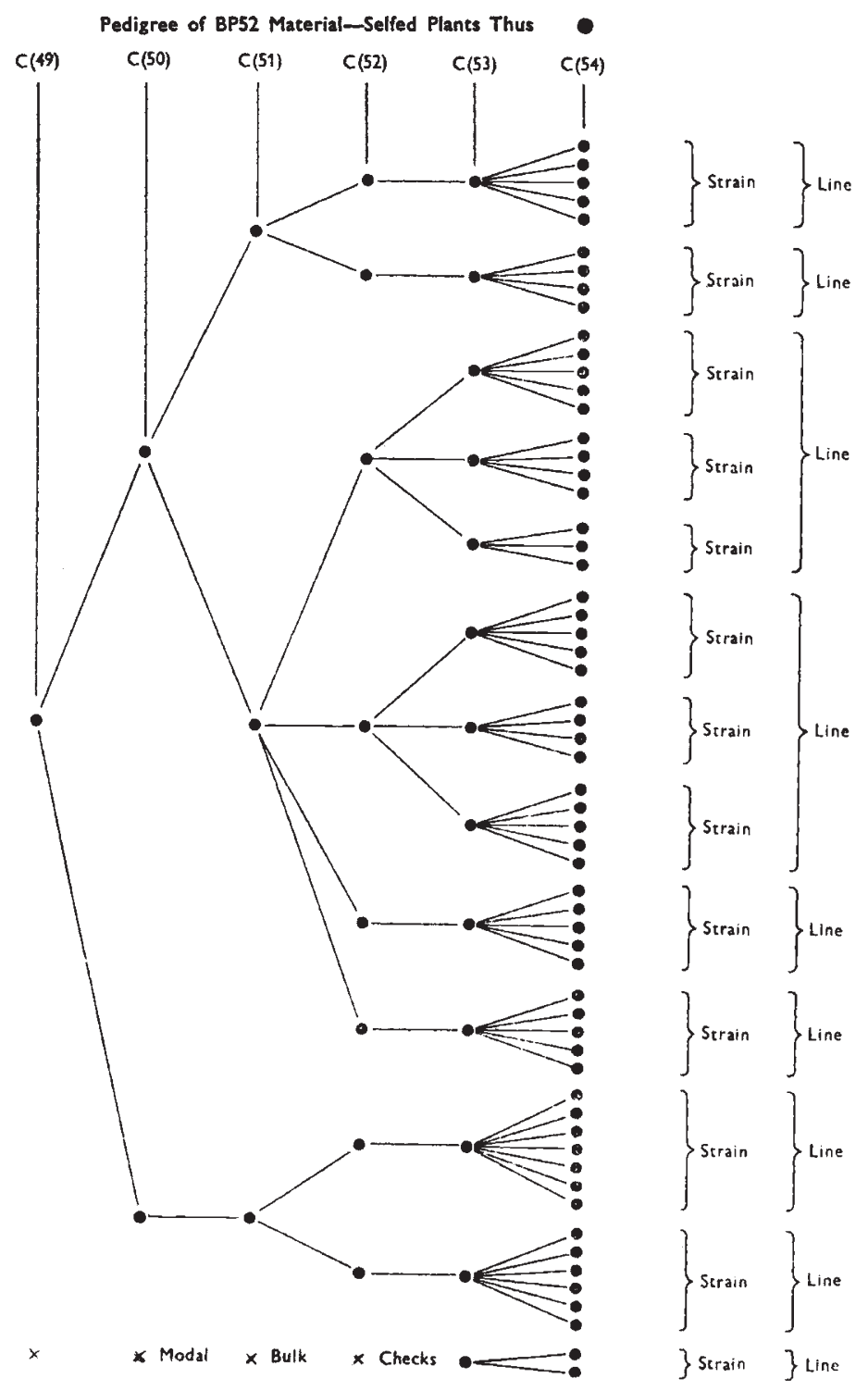

Fig. I.

Data on mean yields are summarised graphically in fig. 2.

In the expectation that they would remain genetically stable, the successive modal bulks were used as standards of comparison. Since in fact a yield advance has been demonstrated in the modal bulk 
series, it is necessary to make an estimate of the annual change in yield of the control series. From the above data it would appear that 3.4 per cent. would be a reasonable figure. The line representing mean yield of the modal bulk standards in fig. 2 is based on this assumption. The points representing yearly means of selected progenies were placed relative to the modal bulk, since the total yield advance must be the sum of the improvement in the standard and the amount by which the progenies excelled the standard. For example, in 1954-55 the indicated advance for selected progenies was $22 \cdot 0$ per cent. (the advantage over the 6 -MB standard) plus $20 \cdot 4$ (the assumed improvement in the standard itself). Six separate

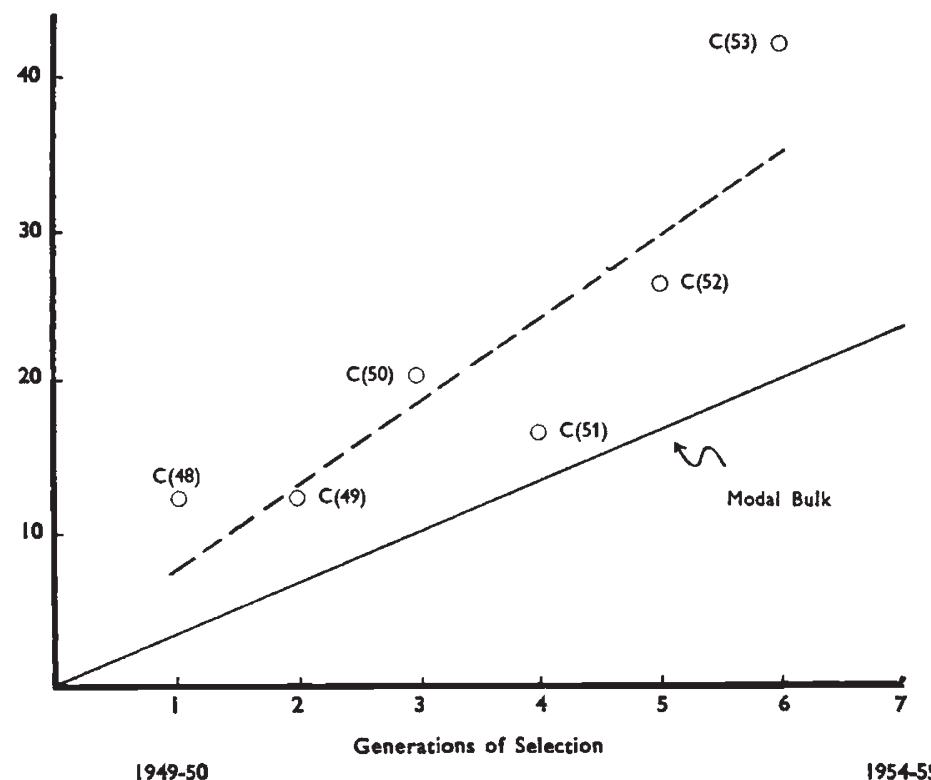

Fig. 2.-Yield improvement of modal bulks and selected progenies over six generations of selection

points are shown and the dotted line is a linear least squares fit to these points. The annual increment, based on the expectation, after six generations of selection, amounts to nearly 6 per cent. This may be compared with the value of 6.3 per cent. per annum derived from the sixth generation in table 6.

District variety trials were conducted in four seasons beginning with 1950-5I. A selection to be tested in any series of these trials was grown from second or third generation open-pollinated bulked seed from a progeny selected two or three years previously. Thus the one included in the first series, $\mathrm{G}\left(4_{8}\right)_{12}$, represents only one generation of progeny row selection. It was grown again in the 195 I-52 series. The progeny $\mathrm{C}(50) 20$ which reflected three generations. 
of selection was also included in successive trials. The check variety in these comparisons was $\mathrm{K} / 5 \mathrm{r}$. Yield data from these trials are summarised in fig. 3 .

The line in this figure represents the linear regression on time of per cent. increment of selected progenies over $\mathrm{K} / 5^{\mathrm{I}}$ and gives an improvement of nearly 20 per cent. after only four generations of selection. This annual increment of nearly 5 per cent. does not differ materially from the 6 per cent. per annum of both the theoretical genetic superiority and that actually achieved from the progeny bulks material.

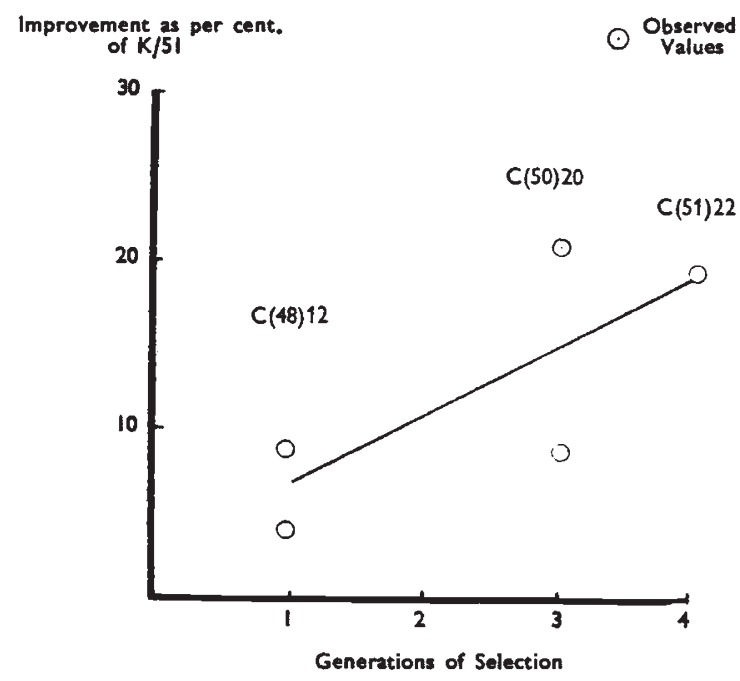

FIG. 3.-Yield improvement of best selected progeny bulk over $\mathrm{K} / 5 \mathrm{I}$ Standard in district variety trials

(iv) Genetic variability in inbred material

Since the progenies of a single strain trace to a common grandparent and the strains of any single line trace to a common great-grandparent, the variation of both progenies within strains and strains within lines provide evidence on the heterozygosity remaining in such ancestral plants after successive generations of inbreeding. Analyses of variance on the data for the successive seasons provided estimates of the components of genetic variance due to progenies in strains and strains in lines. These estimates are presented in table 8.

With a random choice of parents in each generation, the expected number of heterozygous loci is halved by each generation of selffertilisation. Hence, assuming absence of interaction between nonallelic genes, $(a)$ the expected ratio of progeny to strain genetic variance is one-half, and $(b)$ the expected ratio of progeny or strain variance in any year to that in any earlier year is $\left(\frac{1}{2}\right)^{n}$ where $n$ is the number of intervening years.

The estimates shown in table 8 do not form a consistent pattern. Averages over the six years in which estimates of both variances were 
available, indicate that the ratio of progeny to strain variance was roughly in accord with expectation. However, the trend in magnitude of the estimates is quite evidently not in accord with expectation. Most striking are the results for lint per seed, the trait for which the estimates were actually most reliable. For example, the average estimate of progeny variance in the last two years was about one-third that for the first two years whereas the expected ratio is $\left(\frac{1}{2}\right)^{5}$ or $1 / 32$. It should be noted in addition that the progeny variance for this trait was statistically significant in each of the seven seasons.

TABLE 8

Estimates of genetic variance for strains and progenies in strains for traits and yield

\begin{tabular}{|c|c|c|c|c|c|}
\hline Season & Group comparison & Bolls/Plant & Seeds/Bolls & Lint/Seed & Lint/Plant \\
\hline $194^{8-49}$ & Progenies . & $4 \cdot 619^{*}$ & 0.082 & $0.028 *$ & $10.604^{*}$ \\
\hline 1949-50 & $\begin{array}{l}\text { Strains }{ }_{\text {Progenies }} . \\
\end{array}$ & $\begin{array}{l}2 \cdot 605^{*} \\
0\end{array}$ & $\begin{array}{l}1 \cdot 818 * \\
0.436\end{array}$ & $\begin{array}{l}0.094 \\
0.056^{*}\end{array}$ & $\begin{array}{l}1 \cdot 777 \\
0.871\end{array}$ \\
\hline $1950-5 \mathrm{I}$ & $\begin{array}{l}\text { Strains } \\
\text { Progenies : }\end{array}$ & $\begin{array}{l}0 \\
0.273\end{array}$ & $\begin{array}{l}5.218^{*} \\
1 \cdot 54^{*}\end{array}$ & $\begin{array}{l}0 \\
0.055^{*}\end{array}$ & $\begin{array}{l}1 \cdot 227 \\
0.613\end{array}$ \\
\hline $195^{1-52}$ & $\begin{array}{l}\text { Strains } \\
\text { Progenies : }\end{array}$ & $\begin{array}{l}8 \cdot 055^{*} \\
3 \cdot 606^{*}\end{array}$ & $\begin{array}{l}0.106 \\
0 \cdot 452^{*}\end{array}$ & $\begin{array}{l}0 \cdot 118 * \\
0 \cdot 105^{*}\end{array}$ & $\begin{array}{l}9.443^{*} \\
3 \cdot 67^{*}\end{array}$ \\
\hline $1952-53$ & $\begin{array}{l}\text { Strains } \\
\text { Progenies : }\end{array}$ & ${ }_{0}^{1 \cdot 832^{*}}$ & $\begin{array}{l}2 \cdot 779^{*} \\
0 \cdot 14^{2}\end{array}$ & $\begin{array}{l}0.190^{*} \\
0.024^{*}\end{array}$ & $\begin{array}{l}3 \cdot 947^{*} \\
0\end{array}$ \\
\hline I953-54 & $\begin{array}{l}\text { Strains } \\
\text { Progenies : }\end{array}$ & $\begin{array}{l}I \cdot 196^{*} \\
0 \cdot 218\end{array}$ & $\begin{array}{l}0.768^{*} \\
0.53^{*}\end{array}$ & $\begin{array}{l}0.065^{*} \\
0.012^{*}\end{array}$ & $\begin{array}{l}\mathrm{I} \cdot 053^{*} \\
0.397\end{array}$ \\
\hline 1954-55 & $\begin{array}{l}\text { Strains } \\
\text { Progenies : }\end{array}$ & 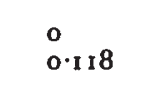 & $\begin{array}{l}0 \\
0.338\end{array}$ & $\begin{array}{l}0.011 \\
0.014 t\end{array}$ & $\begin{array}{l}0.186 \\
0.505^{*}\end{array}$ \\
\hline $\begin{array}{c}\text { Averages } \\
1949-50 \text { to } \\
1954-55\end{array}$ & $\begin{array}{l}\text { Strains } \\
\text { Progenies : }\end{array}$ & $\begin{array}{l}2 \cdot 28 \mathrm{I} \\
0 \cdot 703\end{array}$ & $\begin{array}{l}\mathbf{I} \cdot 78 \mathrm{I} \\
0.575\end{array}$ & $\begin{array}{l}0.080 \\
0.045\end{array}$ & $\begin{array}{l}2 \cdot 939 \\
1 \cdot 009\end{array}$ \\
\hline
\end{tabular}

* Indicates statistical significance at the 5 per cent. level.

$\dagger$ In all but the first season a strain consisted of all progenies tracing to a common grand-parental plant.

\section{DISCUSSION}

(i) Primary selections

Mason (1938) drew attention to the fact that many of the largest and best established improvements in varietal behaviour in cotton were the result of what he called "primary selections". Such selections were made by eye judgment in variable field crops, and gave yield increases perhaps of the order of 25 per cent. He compared with these successes the small improvements, laboriously gained and often difficult to demonstrate decisively, from "secondary selection" carried on by orthodox breeding methods on experiment stations. 
It is in the nature of variability that it should be possible to pick out from an unselected, highly variable crop, components differing widely from the mean. Often, and especially when a crop is comparatively new in an area, or is exposed to such new circumstances as attacks from pests or diseases not previously encountered, selections may be made that will be vastly superior to the unselected material. What is not so generally realised is that the slow, patient, progressive improvement of an already well adapted stock may over the years yield a greater return than a single spectacular stride, and, moreover, that what is known of evolutionary change suggests that this kind of improvement is more comparable with natural evolutionary progress than is the quick response of a successful primary selection.

One of the essential objects of the breeding programme under review was to assess the practicability of breeding for a rather small, but progressive, improvement over a period of years in a stock in which all the major possibilities of advance had already been exploited. Since all the $\mathrm{BP}_{52}$ material traced to a single plant, there was, in 1945, reason to question whether it contained enough genetic variation to provide the basis for significant yield improvement. In fact, however, data from large scale field and district trials indicate a measured yield improvement at the rate of from 5 to 6 per cent. per annum, resulting in a total improvement of some 30 per cent. after six generations of selection.

\section{(ii) Selection index}

The predicted improvement (table 6) from six generations of selection was $3^{8}$ per cent. as compared with the estimate of 35 per cent. provided by the linear regression in fig. 2. This was based on comparisons with the modal bulk checks. District variety trials, conducted over a much wider range of environmental conditions, indicate an annual improvement, relative to $\mathrm{K} / 5 \mathrm{I}$, of approximately 5 per cent. (see fig. 3). In view of the seasonal variation in climatic conditions that occurred, the close approach of the measured to predicted improvement is very impressive. The evidence from the district variety trials is especially encouraging since there is always reason to question whether material, selected at a specific location, will perform at the same high level over an entire area and some variation in management practice.

There is some question regarding the optimum use of data available at any given time. The index was calculated each season entirely on the data pertaining to progenies raised in that season. Alternatively the index might have been adjusted each year in terms of all the accumulated data. The argument for using data from the particular season is that the most effective weighting of several traits is a function of the exact environmental conditions in which the crop was raised. It is well known that genetic variation in a specific trait may be exhibited more clearly in some years than others. This point may be 
demonstrated in another way by considering the expectation of an estimate of genetic covariance in detail. A single plot value may be represented as

$$
\mathrm{P}_{j k m}=\mu+g_{j}+f_{k}+(g f)_{j k}+e_{j k m}
$$

where $\mu \quad$ is the population mean over all years,

$g_{j} \quad$ is the average genotypic effect for the $j$-th progeny,

$f_{k} \quad$ is the effect of the environment of the $k$-th season,

$(g f)_{j k}$ is the effect of interaction between the $j$-th progeny and the environment of the $k$-th season, and

$e_{j k m} \quad$ is a random effect (experimental error) associated with the plot on which the $j$-th progeny is grown in the $m$-th replication.

Working from this model, the expectation of the estimate of the genetic covariance between the $i$-th trait and lint yield is found to be

$$
\sigma g_{i} g_{w}+\sigma(g f)_{i} g_{w}+\sigma g_{i}(g f)_{w}+\sigma(g f)_{i}(g f)_{w} \quad .
$$

The optimum $b$ coefficients would be obtained by using

$$
g_{i w}=\sigma g_{i} g_{w}+\sigma(g f)_{i} g_{w} \text {. }
$$

To estimate $\sigma g_{i} g_{w}+\sigma(g f)_{i} g_{w}$ separately from $\sigma g_{i}(g f)_{w}$ and $\sigma(g f)_{i}(g f)_{w}$ requires data that are beyond the scope of a practical breeding programme. The procedure actually followed estimates the quantity given in equation (3) above. On the other hand, pooling the accumulated data would have provided estimates of the quantity $\sigma g_{i} g_{w}$ plus the mean of the remaining three elements of equation (3) for the seasons for which the data were pooled. This mean would approach zero as the number of seasons was increased. Neither procedures provide exactly what is desired nor is it possible to state with certainty which is better. However, the pooling approach abandons the hope of capitalising on the specificity of the particular season.

An issue of practical importance is the cost in time and effort required for scores or measurements on which the selection index is based. In particular, boll counts are very time consuming and are difficult to obtain with precision. Counts made at a particular time, that must precede the first reaping, will not necessarily include all bolls that may develop soon enough to contribute to the final reaping. The effort involved in repeated counts would be prohibitive. On the other hand, seeds per boll and lint per seed are evaluated at considerably less expense and, in addition, measurement errors are more likely to be detected by routine checks. Fairfield Smith (1936) pointed out that when yield is completely determined by two or more component traits, all available information can be incorporated in the index in terms of either the full set of component traits or by substitution of yield for any one of them. In view of the manner in which measurements were made in this work, yield was not completely 
specified by the data for the three fundamental yield components and, therefore, a slightly more effective index might have resulted from inclusion of lint yield itself. However, the point made by Fairfield Smith (1936) strongly suggests that use of lint yield and any two of the three component traits would supply most of the information available from the three traits and lint yield in this study. Because of the high cost of satisfactory boll counts, it is proposed to use an index based on seeds per boll, lint per seed and lint yield in future selection indices. An illustration of how such an index may compare with that actually used in the past, is provided by computation of the expected genetic superiority associated with these two indices in the case of the 1954-55 data. For the index involving bolls per plant, the expected genetic superiority was computed as $4^{\circ} \circ$ per cent. (table 6) and for the index in which lint yield is substituted for boll number, the comparable figure was 5.4 per cent. In other cases the advantage might not be as great but there is no reason to doubt that lint yield would be at least as effective as boll number.

In the genetic improvement of any crop plant the breeder is always faced with the problem of weighting the wide variety of traits which, in his opinion, have a bearing on the utility of the plant. Almost universally this weighting has been subjective with a great deal of reliance on intuition. The selection index approach provides an objective basis for determining the optimum relative weights to be accorded any combination of characters. It requires only that a quantitative measure is provided for each character. The $b$ coefficients indicate the proper attention to be given each and if it approximates to zero, this is not to infer that the character itself is of no physiological significance whatsoever. What it does mean is that the appropriate attention to the trait is provided indirectly through the emphases accorded to the related traits. The approach outlined here appears apposite as a basis for incorporating resistance to bacterial blight into the Uganda selection programme.

While evidence has been presented for persistence of genetic variability within continuously self-fertilised lines of cotton, it is now unlikely that the magnitude of such variation would justify a continued major programme of selection within inbred lines. On the other hand this persisting genetic variation provides the opportunity for effecting adjustments of minor weaknesses in otherwise superior strains. Moreover, a panmictic population, derived from inter-crosses of selection lines, should exhibit nearly the same order of genetic variability that was demonstrated by $\mathrm{BP}_{52}$ itself. Such a population should reflect the effect of selection practised thus far and therefore provide a higher base to build through future selection.

\section{(iii) Persistence of genetic variability}

Continuous self-fertilisation is widely used with diploid organisms for developing lines within which there is a minimum of genetic 
variation. New World cottons, though amphidiploid in origin, are usually considered to function as diploids. Thus a question arises concerning the utility of selection at all within lines that have resulted from more than a few generations of inbreeding. The present data are not the first suggestion that appreciable genetic variation may persist in the face of continuous self-fertilisation of cotton. In this connection Hutchinson (1940) commented on the failure to achieve "pure lines" in Sea Island cotton. Harland (1934) reported that after I 3 generations of self-fertilisation, selection for lint index (lint per seed) in the Montserrat Sea Island variety of cotton still led to yield improvement. Similar results were obtained by the writer in I 944 using material of a hybrid between the Montserrat and St Vincent Sea Island varieties. After five generations of inbreeding, during which time selection intensity was low, a new programme was designed to direct intense selection in three directions. In one population, selection pressure was exerted in favour of boll number, ignoring other traits and, in another, similar pressure was exerted in favour of the trait lint per seed. In a third, selection was based on yield only. This procedure was followed for the next six seasons always using selffertilised material for selection. At the end of this period estimates of genetic variances for progenies in strains were as follows :

\begin{tabular}{|c|c|c|}
\hline \multirow{2}{*}{ Objective in selection } & \multicolumn{2}{|c|}{ Genetic variance for traits } \\
\hline & Bolls per plant & Lint per seed (CGM) \\
\hline High boll number . & I5.597* & $0.0223 \dagger$ \\
\hline High lint per seed . & 0.339 & $0 \cdot 1076^{*}$ \\
\hline Yield only . . & $5 \cdot 912$ & $0.005^{2}$ \\
\hline
\end{tabular}

As in the case of the comparable Uganda data, the observed variances are considerably in excess of the residual variances which might be expected in a functional diploid after the same indicated number of generations of inbreeding. It is of interest to note that the largest estimates of genetic variance in individual traits were obtained in populations in which selection pressure was confined to the trait in question. Such extremes were not observed in the St Vincent population in which selection was for yield (a composite of several traits), or in the Uganda material where the selection criterion gave some weight to each of three characters.

There are a number of possible explanations for persistence of variability in inbred cotton, one of which is undoubtedly that with the statistical techniques that were used, it was possible to detect those strains in which there was sufficient genetic variation to provide 
scope for further improvement. The problem is further discussed elsewhere (Manning, I955). It is sufficient here to emphasise that genetic variation of a magnitude to lead to practical yield improvement has been demonstrated to exist after seven generations of inbreeding, and there is some evidence for the view that a breeding programme can be so designed as to conserve the variability necessary for further improvement.

\section{(iv) Selection in the modal bulk}

The genetic improvement demonstrated for the modal bulk population indicates that, contrary to the original intent, some form of selection pressure for yield must have been operative. It is of interest to speculate on the ways in which this may have occurred. At least three possibilities can be envisaged.

\begin{tabular}{|c|c|}
\hline Season & $\begin{array}{c}\text { Selection differential } \\
\text { (per cent.) }\end{array}$ \\
\hline & $7 \cdot 8$ \\
$1947-48$ & $3 \cdot 9$ \\
$1948-49$ & $3 \cdot 1$ \\
$1949-50$ & $0 \cdot 1$ \\
$1950-51$ & $1 \cdot 2$ \\
$1951-52$ & $6 \cdot 2$ \\
$1952-53$ & $6 \cdot 3$ \\
$1953-54$ & $4 \cdot 0$ \\
\hline Average & \\
\hline
\end{tabular}

It will be recalled that there were actually two stages of selection. The first consisted of taking a sample of 300 to 500 plants from a field of some 6000 plants. Secondly, the modal selection practised in the sample of plants actually taken from the field itself, resulted in a positive selection differential for yield. The differences in the mean lint yield of the plants from which seed was actually used, and of the entire sample from which they were taken, are listed above in per cent. of the mean for the entire sample.

The mechanism by which these differences arose is uncertain but either non-linear relations between yield and the traits on which the modal selection was based, or asymmetrical distribution of one or more of the latter, are indicated. Unless the heritability of yield in single plants was very considerably more than it is reasonable to suppose, a selection differential of no more than 4 per cent. could have contributed only a small part of the annual genetic improvement previously indicated.

Finally, the effects of automatic selection incidental to the close relationship between seed number and yield would be a contributing factor of some importance.* The effective selection differential above

* This explanation was put forward by Dr R. E. Comstock of the Institute of Statistics, North Carolina State College. 
$\overline{\mathrm{Y}}$, the unweighted mean for plants from which seeds were actually bulked would be computed as $\Sigma \mathrm{XY} / \Sigma \mathrm{X}-\overline{\mathrm{Y}}$ where $\mathrm{X}$ is number of seeds per plant, $\mathrm{Y}$ is yield per plant, and summation is over all plants. It may be estimated on the basis of the following argument. Assuming linear regression of $\mathrm{Y}$ and $\mathrm{X}$, which was clearly demonstrated in the data,

$\mathrm{Y}=\overline{\mathrm{Y}}+\beta_{\mathrm{YX}}(\mathrm{X}-\overline{\mathrm{X}})+\mathrm{a}$ random deviation from regression.

Then integrating $\mathrm{XY} f(\mathrm{X})$ and $\mathrm{X} f(\mathrm{X})$ over the range of the distribution

$$
\overline{\mathrm{Y}} \overline{\mathrm{X}}+\beta_{\mathrm{XY}} \sigma_{\mathrm{X}}^{2} \text { and } \overline{\mathrm{X}}
$$

are obtained. Dividing the former by the latter

$$
\overline{\mathrm{Y}}+\frac{\beta \sigma_{\mathrm{X}}^{2}}{\overline{\mathrm{X}}}
$$

is obtained as the expectation of $\Sigma \mathrm{XY} / \Sigma \mathrm{X}$. Substituting estimates of the several parameters, the selection differential in per cent. of the mean is approximated as 12 or 13 per cent. Values of the selection differential as outlined were compared with actual values of

$$
(\Sigma \mathrm{XY} / \Sigma \mathrm{X})-\overline{\mathrm{Y}}
$$

computed from the single plant data for two years. The agreement was satisfactory. Since the automatic selection differential was in addition to that resulting from the modal selection, estimates of the two may appropriately be summed to obtain a total estimate of 16 or 17 per cent. Assuming a heritability (on the single plant basis) of from Io to I 5 per cent., which is not incompatible with the estimates of genetic variance in the inbred material and the phenotypic variance of single plants, this would allow for an annual improvement of from I. 7 to 2.55 per cent. This compares with the 3.4 per cent. indicated by yield trials, a portion of which may have resulted from the field selection of the sample in which modal selection was practised.

\section{SUMMARY}

I. A Selection Index technique was employed to bring about yield improvement in self-fertilised material of the $\mathrm{BP}_{52}$ Upland variety of cotton grown extensively in Uganda.

2. Genetic advance of the order of 35 per cent. was recorded after six generations of selection.

3. It was inferred that considerable genetic variability must have been present in the original material. Moreover, its persistence in the face of self-fertilisation provides a justification for continued selection within inbred material.

4. While only the primary components of yield, namely, bolls per plant, seeds per boll and lint per seed were actually used as the basis for the selection index in this work, attention is drawn to the fact that additional factors may be included for any traits which appear truly different to the eye. 
5. The improvement in the modal bulk check standard suggests that natural selection favours the breeder whenever number of seeds produced is intimately related to yield.

Acknowledgments.- This paper represents the completion of a co-operative project between the Empire Cotton Growing Corporation and the Institute of Statistics at North Carolina State College. The writer is greatly indebted to the Directors of the respective organisations for having the opportunities of discussing the various aspects of the work with the geneticists and statisticians at North Carolina State College. In particular, the writer would like to acknowledge his indebtedness to Dr R. E. Comstock for his patient interest and helpfulness in regard to the statistical genetics involved in this work. Finally, the writer would like to acknowledge many invaluable suggestions from $\mathrm{Dr}$ J. B. Hutchinson, F.R.s., throughout the course of this project.

\section{REFERENCES}

FISHER, R. A., AND YATES, F. 1948. Statistical Tables. Oliver and Boyd, Edinburgh, 3 rd Ed.

Goulden, c. H. 1939. Methods of Statistical Analysis. John Wiley, New York, p. 229. harland, s. c. 1934. Rept. Summ. Proc. 2nd Conf. Cotton Breeding Problems, Empire Cotton Growing Corporation, London.

HAZEL, L. N. 1943. Genetic basis for selection indexes. Genetics, 28, 476-490.

HAZEL, L. N., AND LUSH, J. L. 1942. The efficiency of three methods of selection. F. Hered., 33, 393-399.

hutchinson, J. B. 1940. The application of genetics to plant breeding I. $\mathcal{F}$. Genet., $40,271-282$.

hUtchinson, J. B., AND PANSE, v. G. 1937. Further studies in the technique of field experiments. Ind. F. Agric. Sci., 7, 53 I.

LERNER, I. M., ASMUNDSON, v. s., AND CRUDEN, DOROTHY M. 1947. The improvement of New Hampshire Fryers. Poultry Science, 26, 515-524.

MANNing, H. L. 1955. Cold Spring Harbor Symposia. (In press.)

MASON, T. G. 1938. A note on the technique of cotton breeding. Emp. Cott. Growing Rev., $15,113-117$.

ROBINSON, H. F., COMSTOCK, R. E., AND HARVEY, P. H. 1951. Genotypic and phenotypic correlations in corn and their implications in selection. Agron. F., 43, 282-287.

SNEDECOR, G. W. 1953. Statistical Methods. Ames, Iowa, 4th Ed., p. 234 .

SMith, H. FAIRFIELD. 1936. A discriminant function for plant selection. Annals of Eugenics, 7, 240-250. 